\title{
Daxx is required for stress-induced cell death and JNK activation
}

\author{
AF Khelifi ${ }^{1}$, M Stagno D'Alcontres ${ }^{1}$ and P Salomoni ${ }^{\star, 1}$ \\ ${ }^{1}$ MRC Toxicology Unit, University of Leicester, Leicester, UK \\ * Corresponding author: P Salomoni, MRC Toxicology Unit, University of \\ Leicester, Lancaster Road Box 138, Leicester, UK. Tel: + 44116 2525568; \\ Fax: + 44116 2525616; E-mail: ps90@le.ac.uk
}

Received 20.8.04; revised 09.11.04; accepted 15.11.04; published online 29.4.05 Edited by RA Knight

\section{Abstract \\ Daxx has been implicated in the modulation of apoptosis in response to various stimuli. In the nucleus, Daxx interacts and colocalizes with the promyelocytic leukemia protein (PML) into the PML-nuclear body. Moreover, overexpressed Daxx positively modulates FAS-ligand and TGF $\beta$-induced apoptosis. However, recent reports indicate that Daxx can also act as an antiapoptotic factor. As most studies on the role of Daxx in cell death have been conducted using tumour cell lines, we analysed the function of Daxx in physiological settings. We found that Daxx is induced upon exposure to ultraviolet (UV) irradiation and hydrogen peroxide treatment. We employed RNA interference to downregulate Daxx in primary fibroblasts. Remarkably, Daxx-depleted cells are resistant to cell death induced by both UV irradiation and oxidative stress. Furthermore, the downregulation of Daxx results in impaired MKK/c-Jun-N-terminal kinase (JNK) activation. This is the first evidence that Daxx promotes cell death and JNK activation in physiological conditions. Cell Death and Differentiation (2005) 12, 724-733. \\ doi:10.1038/sj.cdd. 4401559 \\ Published online 29 April 2005}

Keywords: daxx; cell death; stress kinases

\begin{abstract}
Abbreviations: JNK, c-Jun-N-terminal kinase; PML, promyleocytic leukaemia protein; PML-NB, PML nuclear body; ASK1, apoptosis signal regulating kinase 1; UV, ultraviolet irradiation; RNAi, RNA interference; MAPK, mitogen activated kinase; MAPKK, MAP kinase kinase; $\mathrm{H}_{2} \mathrm{O}_{2}$, hydrogen peroxide; BrdU, 5-bromo-2'-deoxyuridine
\end{abstract}

\section{Introduction}

Daxx was originally identified as a Fas-interacting protein that specifically binds to the Fas death domain. ${ }^{1}$ Daxx overexpression was shown to enhance Fas-mediated apoptosis and activate the c-Jun-N-terminal kinase (JNK) pathway independently of FADD, thereby suggesting that Daxx functions as a proapoptotic protein downstream of Fas. ${ }^{1,2}$ Daxx was found to interact and activate the upstream JNK kinase kinase ASK1, providing a link between Fas and JNK activation through cytoplasmic ASK $1 .^{3}$ More recently, Daxx was also shown to interact with ASK1 upon glucose deprivation. ${ }^{4}$ However, Daxx has been reported to be present exclusively in the nucleus and to localize into the promyelocytic leukemia protein nuclear body (PML-NB), ${ }^{5-7}$ thereby challenging the above-attributed cytoplasmic functions. In fact, attempts at reproducing the initial studies demonstrating interaction between Daxx and Fas were unsuccessful as no evidence of association between human Daxx and the cytosolic domain of human Fas were found in two-hybrid assays and coimmunoprecipitation experiments. ${ }^{8}$ In addition, despite the fact that overexpressed human Daxx increased apoptosis induction by anti-Fas, no activation of JNK was evident in either human Daxx-overexpressing cells or following their stimulation with an anti-Fas antibody. ${ }^{8}$

Several studies have addressed the potential cytoplasmic versus nuclear roles of Daxx. Overexpression studies have reported that Daxx localizes to the cytoplasm and mediates Fas signalling only in the presence of overexpressed ASK $1 .{ }^{9}$ However, the physiological significance of these findings remains to be verified. Others demonstrated the ability of Daxx to shuttle from the nucleus into the cytoplasm upon various stresses. ${ }^{10,11}$ There is evidence that Daxx phosphorylation is required for its cytoplasmic relocalization and activation of ASK1 upon glucose deprivation. ${ }^{11}$ However, contradictory reports have shown that Daxx is able to promote sensitivity to FAS-induced apoptosis from its nuclear location through modulation of gene transcription. ${ }^{8}$

Indeed, Daxx is also known to regulate transcription by acting as a transcriptional corepressor. Daxx was shown to interact with several transcription factors and to repress their transcriptional activity; these include Pax $3,{ }^{12}$ ETS1, ${ }^{13}$ E2F1, ${ }^{14}$ $\mathrm{NF}_{\kappa} \mathrm{B},{ }^{14}$ and $\mathrm{p}^{14}{ }^{15}{ }^{15}$ Furthermore, Daxx was reported to interact with several crucial proteins involved in transcriptional silencing namely histone deacetylase II, core histones and the chromatin-associated protein DEK, providing a potential mechanism by which Daxx is able to repress transcription. ${ }^{16}$

Daxx overexpression was not only reported to sensitize cells to Fas-induced apoptosis, but also to ultraviolet (UV) irradiation ${ }^{17}$ and TGF $\beta$ stimulation. ${ }^{18}$ Moreover, the proapoptotic function of Daxx is impaired in PML-deficient cells, thus suggesting that the two proteins participate in a nuclear pathway for cell death. ${ }^{6}$ Downregulation of Daxx by RNA interference (RNAi) modestly protects cells from arsenite trioxide $\left(\mathrm{As}_{2} \mathrm{O}_{3}\right)$ and interferon-gamma (IFN $\left.\gamma\right){ }^{19}$ However, despite these several reports claiming the proapoptotic role of Daxx, its exact function in cell death remains controversial because of numerous contradictory studies. Firstly, disruption of the Daxx gene in mice resulted in early embryonic lethality and extensive apoptosis. ${ }^{20}$ More recently, Daxx silencing by RNAi in cell lines was reported either to increase apoptosis ${ }^{14}$ or to sensitize cells to Fas-, UV- and TNF- $\alpha$-induced apoptosis, ${ }^{21}$ suggesting an antiapoptotic role of Daxx.

The aim of the present study was to further clarify the role of Daxx in stress-induced death of primary cells. Previous 
studies in primary keratinocytes demonstrated that Daxx overexpression induces cell death. ${ }^{6}$ Here, the role of Daxx was investigated in more physiological conditions by using RNAi in human primary fibroblasts. The importance of Daxx in cell death was investigated following exposure to genotoxic and oxidative stress and the involvement of the JNK pathway was examined. We found that in the absence of Daxx, primary fibroblasts are protected from both ultraviolet (UV)- and hydrogen peroxide $\left(\mathrm{H}_{2} \mathrm{O}_{2}\right)$-induced cell death, suggesting that Daxx actively participates in the death process and acts as an antisurvival molecule. Upon both $\mathrm{UV}$ and $\mathrm{H}_{2} \mathrm{O}_{2}$ exposure, activation of the JNK pathway was significantly impaired in Daxx-depleted cells, and so was the upstream JNK kinase MKK4/SEK1, suggesting that Daxx has regulatory functions upstream of JNK.

\section{Results}

\section{Effects of genotoxic and oxidative stress on Daxx protein levels}

We analysed the expression levels of Daxx upon exposure of primary human fibroblasts (BJ) to different cellular stresses. Remarkably, UV-C irradiation $\left(80 \mathrm{~J} / \mathrm{m}^{2}\right)$ caused induction of Daxx protein levels as early as $3 \mathrm{~h}$ following irradiation (Figure 1a). Daxx protein levels remained elevated at $12 \mathrm{~h}$ following irradiation but returned to control levels by $24 \mathrm{~h}$ (Figure 1a). As Daxx has been recently involved in the regulation of the cellular response to oxidative stress, we set to study the effects of $\mathrm{H}_{2} \mathrm{O}_{2}$ on the expression of Daxx. Upon treatment of BJ with non-cytotoxic doses of $\mathrm{H}_{2} \mathrm{O}_{2}$ (25 or $50 \mu \mathrm{M})$, Daxx protein levels were clearly induced at 2 and $3 \mathrm{~h}$ as shown by Western blotting (Figure 1b). Furthermore, Daxx was also induced by $\mathrm{H}_{2} \mathrm{O}_{2}(250 \mu \mathrm{M})$ in immortalized mouse embryo fibroblasts (not shown). These results clearly suggest an important role of Daxx in the response of primary fibroblasts to various cellular stresses.
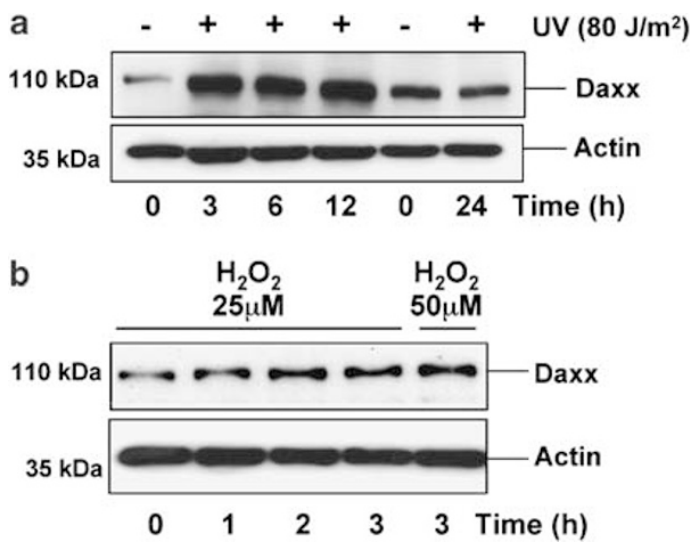

Figure 1 Daxx protein levels are induced in response to UV-C irradiation and hydrogen peroxide $\left(\mathrm{H}_{2} \mathrm{O}_{2}\right)$. (a) BJ cells were exposed to UV-C irradiation $(80 \mathrm{~J} /$ $\mathrm{m}^{2}$ ) and cell lysates were prepared at the indicated time points. Western blot analysis of the cell lysates shows an increase in Daxx protein levels in response to UV-C at 3,6 and $12 \mathrm{~h}$. (b) BJ cells were treated with $\mathrm{H}_{2} \mathrm{O}_{2}(25$ or $50 \mu \mathrm{M})$ and cell lysates were prepared at the indicated time points. Western blot analysis of the cell lysates shows an increase in Daxx protein levels in response to $\mathrm{H}_{2} \mathrm{O}_{2}$ at 1 , 2 and $3 \mathrm{~h}$

\section{Daxx depletion in primary fibroblasts by RNAi}

In order to determine the role of Daxx in the cellular response to stress, we undertook an RNAi approach to downregulate its levels in primary cells. We developed an electroporation protocol specifically designed to introduce double-stranded RNA oligonucleotides (oligos) into primary cells. Cell viability following electroporation ranged between 50 and $60 \%$, and the viable cells fully recovered at $48 \mathrm{~h}$ (not shown). We tested three different oligos directed against Daxx mRNA (D9, D42, D3) and one scrambled oligo (SO) that is not complementary to any sequence in the genebank. Daxx protein levels were successfully downregulated following the introduction of all the different short double-stranded RNA oligos at both 48 and $72 \mathrm{~h}$ (Figure 2a). Furthermore, there were no differences in Daxx protein levels between SO-transfected cells and noninterfered BJ cells (See Supplementary Information, Figure S1). The Daxx oligo designated D9 was the least effective at downregulating Daxx protein at all the time points examined (Figure 2a). At 96h, the effectiveness of the single electroporated oligos D9, D42 and D3 at downregulating Daxx protein started to decrease, while the combination of D9 and D42 oligos (D9/D42) was the most effective at this time point (Figure 2a). Therefore, all subsequent RNAi experiments were carried out using the D9/D42 combination. Knockdown efficiency following the introduction of D9/D42 oligos was in the range of $90 \%$ at $48 \mathrm{~h}$ and was maintained down to the same level at $72 \mathrm{~h}$ (Figure $2 \mathrm{a}, \mathrm{b}$ ). RNA oligos directed against Lamin A/C also caused downregulation of Lamin A/C protein levels, although silencing was less pronounced (Figure 2b). In order to confirm the data obtained by Western blotting, we performed immunofluorescence analysis with an anti-Daxx antibody. As shown in Figure 2c, Daxx is nuclear and accumulates in the PML-NB in SO-transfected cells. Conversely, Daxx staining was efficiently shut down in D9/D42transfected cells. As Daxx accumulates in the PML-NB, ${ }^{5-7}$ we analysed whether Daxx depletion could affect PML localization. We found that PML still accumulates in nuclear speckles upon Daxx downregulation, thus demonstrating that Daxx is not essential for the formation of the PML-NB (Figure 2d).

Our RNAi technique was also effective at downregulating Daxx and Lamin A/C in WI38 human embryonic lung fibroblasts and immortalized mouse embryo fibroblasts (not shown).

\section{Effects of Daxx downregulation on cell viability and proliferation}

As Daxx silencing by RNAi in HeLa cells was reported to result in increased levels of apoptosis, ${ }^{14}$ experiments were carried out examining cell viability following Daxx silencing in our primary cell system. At $48 \mathrm{~h}$ following electroporation, the morphology of Daxx-depleted cells was normal, and few floating cells were observed (Figure 3a). Cell viability was determined at $48 \mathrm{~h}$ following electroporation with the D9/D42 oligos using the trypan blue exclusion assay. As shown in Figure $3 b$, no significant increase in the percentage of cell death was detected in Daxx-depleted cells compared to control cells. Therefore, Daxx does not play a survival role in primary cells, contradicting previously reported data in tumour 

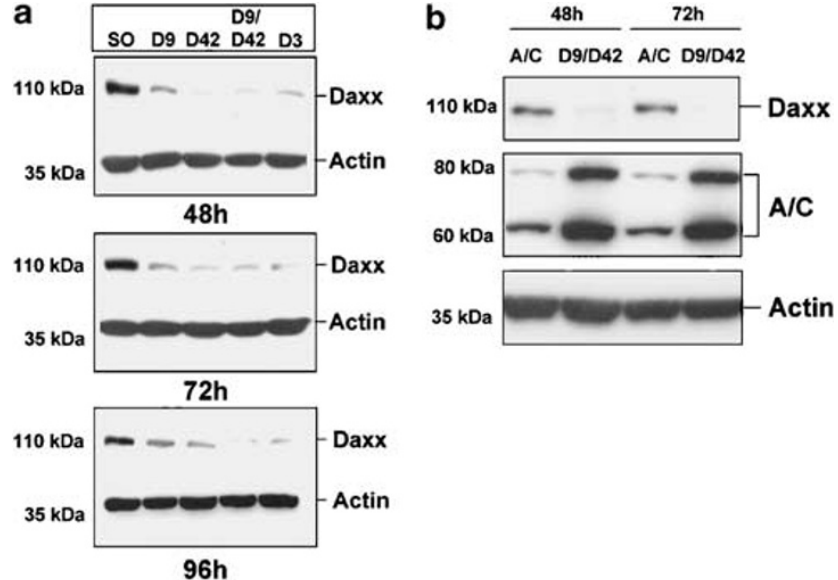

C
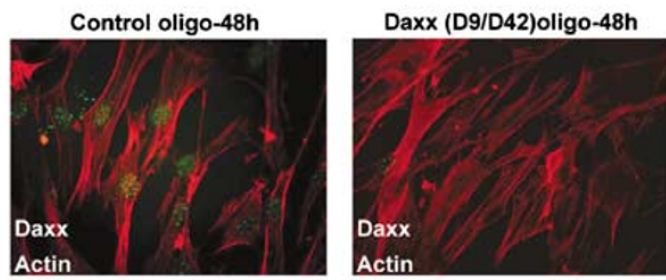

d
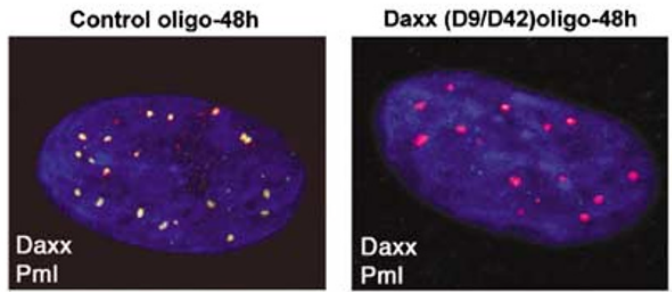

Figure 2 Daxx silencing by RNAi in BJ primary fibroblasts. (a) BJ cells were electroporated with scrambled oligo (SO), Daxx oligo D9, Daxx oligo D42, the combination oligos D9/D42 or the Daxx oligo D3 and cell lysates were prepared at 48,72 and $96 \mathrm{~h}$. Western blot analysis of the cell lysates shows Daxx protein downregulation at the indicated time points following introduction of the Daxx oligos. (b) BJ cells were electroporated with the Daxx oligos D9/D42 or Lamin A/ $\mathrm{C}$ oligos as a positive control, and cell lysates were prepared at 48 and $72 \mathrm{~h}$. Western blot analysis of the cell lysates shows Daxx and Lamin A/C protein downregulation at the indicated time points following introduction of the respective oligos. (c) BJ cells were electroporated with control oligo or Daxx oligos D9/D42 and formalin-fixed at 48h. The images show Daxx (green) and actin (red) stained by immunofluorescence using an anti-Daxx antibody and rhodamine tagged-phalloidin, respectively. (d) BJ cells were electroporated with control oligo or Daxx oligos D9/D42 and formalin-fixed at $48 \mathrm{~h}$. The merged confocal images show Daxx (green) and PML (red) stained by immunofluorescence using an anti-Daxx antibody and an anti-PML antibody, respectively. Nuclei were counterstained with DAPI (blue)

cell lines. ${ }^{14}$ The potential role of Daxx in the regulation of cell proliferation was also investigated. Equal numbers of viable cells $\left(2 \times 10^{5}\right)$ were plated after electroporation $(0 \mathrm{~h})$, and cells were then counted at $96 \mathrm{~h}$ following electroporation. Again, no significant differences in proliferation were observed between Daxx-depleted BJ and controls (Figure 3c). These results were confirmed by carrying out a 5-bromo-2'-deoxyuridine (BrdU) incorporation assay, where no differences in BrdU incorporation were measured between Daxx-depleted cells and controls (not shown). Thus, Daxx does not regulate cell proliferation in primary fibroblasts.
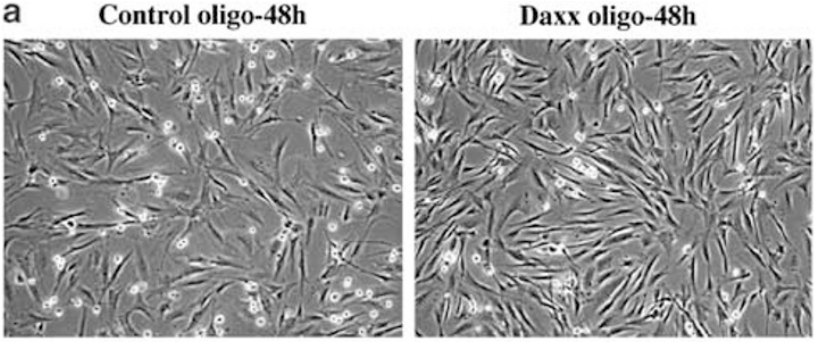

b
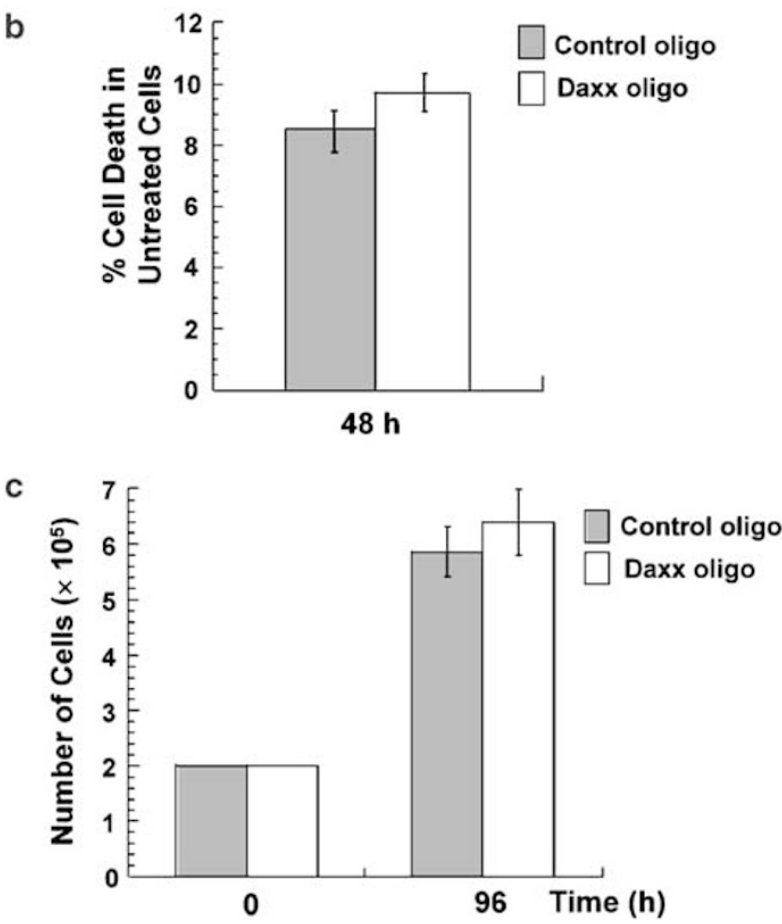

Figure 3 Daxx downregulation does not affect cell death or proliferation. (a) Phase contrast images of control (SO-transfected) and Daxx-depleted cells at $48 \mathrm{~h}$ following electroporation of control or D9/D42 oligos. (b) Assessment of the percentage cell death in control and Daxx-depleted cells at $48 \mathrm{~h}$ following electroporation of control or D9/D42 oligos using the trypan blue exclusion assay. Data are means of at least three experiments performed in duplicates. Error bars are means \pm 1 standard error of the mean. (c) Assessment of cell proliferation in control and Daxx-depleted cells at $96 \mathrm{~h}$ following electroporation of control or D9/ D42 oligos. Equal numbers of cells were plated on electroporation day (0) and cells were counted at $96 \mathrm{~h}$ using a haemocytometer. Data are means of at least three experiments performed in duplicates. Error bars are means \pm 1 standard error of the mean

\section{Effects of Daxx downregulation on UV- and $\mathrm{H}_{2} \mathrm{O}_{2}$-induced cell death}

In order to clarify the controversy with regard to the role of Daxx in the regulation of cell death, we conducted a series of experiments examining the effects of Daxx downregulation on cell death induced by UV and $\mathrm{H}_{2} \mathrm{O}_{2}$ treatments. Control and Daxx-depleted BJ cells were exposed to either stimuli and cell death was assessed by the trypan blue exclusion assay. Cells were irradiated $\left(80 \mathrm{~J} / \mathrm{m}^{2}\right)$ at $48 \mathrm{~h}$ following electroporation and cell death was assessed $48 \mathrm{~h}$ later. We found that upon exposure to UV irradiation, Daxx-depleted cells were significantly more resistant to cell death compared to control cells. In fact, at $48 \mathrm{~h}$ after UV irradiation, $46.71 \%$ of control 
cells appeared trypan blue positive (5.4-fold induction in cell death), compared to only $22.96 \%$ (2.3-fold induction) in the Daxx-depleted cells (Figure 4a). To determine whether the effects on cell death were specific, we carried out experiments

a

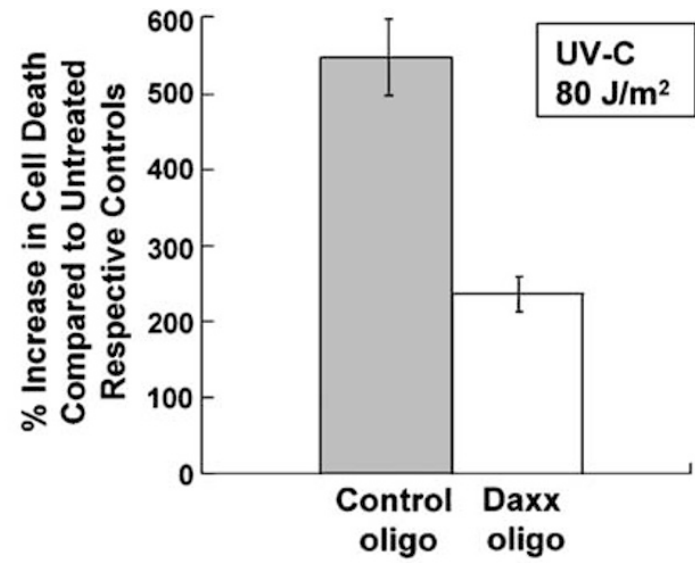

b

Untreated Control Oligo

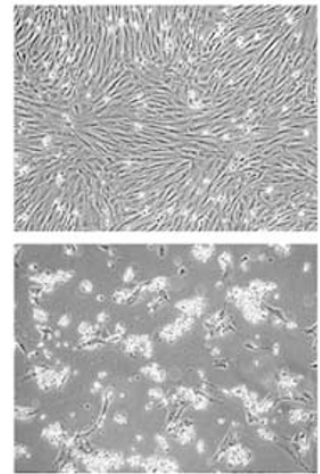

UV-C 48h

C

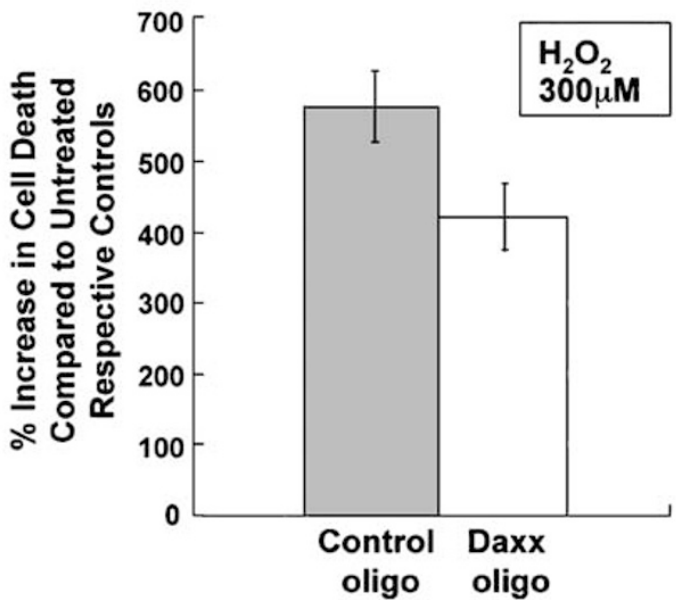

Figure 4 Daxx silencing confers resistance to stress-induced death of primary fibroblasts. (a) Assessment of cell death induction in control (SO-transfected) and Daxx-depleted BJ cells at $48 \mathrm{~h}$ following exposure to UV-C irradiation $\left(80 \mathrm{~J} / \mathrm{m}^{2}\right)$. The data are means of at least three experiments performed in duplicates. Error bars are means +1 standard error of the mean. (b) Phase contrast images of control and Daxx-depleted BJ cells untreated and exposed to UV-C at $48 \mathrm{~h}$. (c) Assessment of cell death induction in control and Daxx-depleted BJ cells at $4.5 \mathrm{~h}$ following continuous exposure to $\mathrm{H}_{2} \mathrm{O}_{2}(300 \mu \mathrm{M})$. The data are means of at least three experiments performed in duplicates. Error bars are means \pm 1 standard error of the mean using the three different RNAi oligonucleotides (D3, D9, D42) and the D9/D42 combination (not shown). Remarkably, the extent of Daxx downregulation directly correlated with the degree of protection from UV-induced cell death (not shown). Furthermore, the differences in sensitivity to UV-induced cell death between controls and Daxx-depleted cells were also evident morphologically as shown by the phase contrast images in Figure 4b. Indeed, we could observe a significantly greater number of rounded floating cells in control cells compared to Daxx-depleted cells at $48 \mathrm{~h}$ following UV irradiation. Moreover, while the control surviving cells assumed a flattened morphology, the Daxx-depleted surviving cells seemed to cluster in islands and assumed long projections, suggesting cytoskeletal alterations (Figure 4b). Finally, as protection from UV-induced cell death often correlates with cell cycle arrest, ${ }^{22}$ we determined whether in Daxx-depleted cells the block of proliferation was more robust following irradiation. The UV-triggered proliferation block was, however, comparable in control and Daxx-depleted cells, thus indicating that cell cycle alterations were not likely involved (not shown).

In order to study the response of BJ cells to $\mathrm{H}_{2} \mathrm{O}_{2}$ treatment, a series of experiments were initially carried out to determine the dose of $\mathrm{H}_{2} \mathrm{O}_{2}$ and incubation times required to induce cell death. We found that $300 \mu \mathrm{M}$ for $4.5 \mathrm{~h}$ of continuous incubation was the optimal dose and exposure time to induce around $60 \%$ cell death, whereas doses lower than $300 \mu \mathrm{M}$ only induced cell cycle arrest and doses above caused massive cell death. In response to $\mathrm{H}_{2} \mathrm{O}_{2}$, Daxx-depleted cells were also resistant to cell death, although to a lesser extent than to UV. Figure 4c shows that there was a 5.7-fold increase in cell death in control cells (66.67\% trypan blue positive) after $4.5 \mathrm{~h}$ of continuous incubation with $\mathrm{H}_{2} \mathrm{O}_{2}(300 \mu \mathrm{M})$, compared to a 4.2 -fold increase in the Daxx-depleted cells $(45.07 \%$ trypan blue positive) exposed to the same conditions. No dramatic differences in morphology were observed between control and Daxx-depleted cells following treatment with $\mathrm{H}_{2} \mathrm{O}_{2}$ (not shown).

\section{Effects of Daxx downregulation on the p53 pathway, Bcl-2 family members and caspases}

Exposure to UV irradiation is known to result in the stabilization and accumulation of the tumour suppressor $p 53,{ }^{23,24}$ which then leads to the induction of several target genes including the cell cycle regulator p21 and the proapoptotic Bcl2 family member Bax. ${ }^{25}$ We examined in our primary cell system whether the increased resistance to UV-induced cell death observed in Daxx-depleted cells could be explained by an impaired activation of the p53 pathway. Figure $5 \mathrm{a}$ demonstrates that there was no differential regulation in either p53 or Bax protein levels between control and Daxx-depleted cells. On the other hand, the cell cycle regulator p21 was downregulated shortly after UV exposure (Figure 5a), as previously reported. ${ }^{26}$ The protein levels of p21 recovered at the later time points of 6 and $8 \mathrm{~h}$ (not shown), but again there were no differences between controls and Daxxdepleted cells. These results suggest that under these conditions Daxx does not regulate the p53 pathway. 


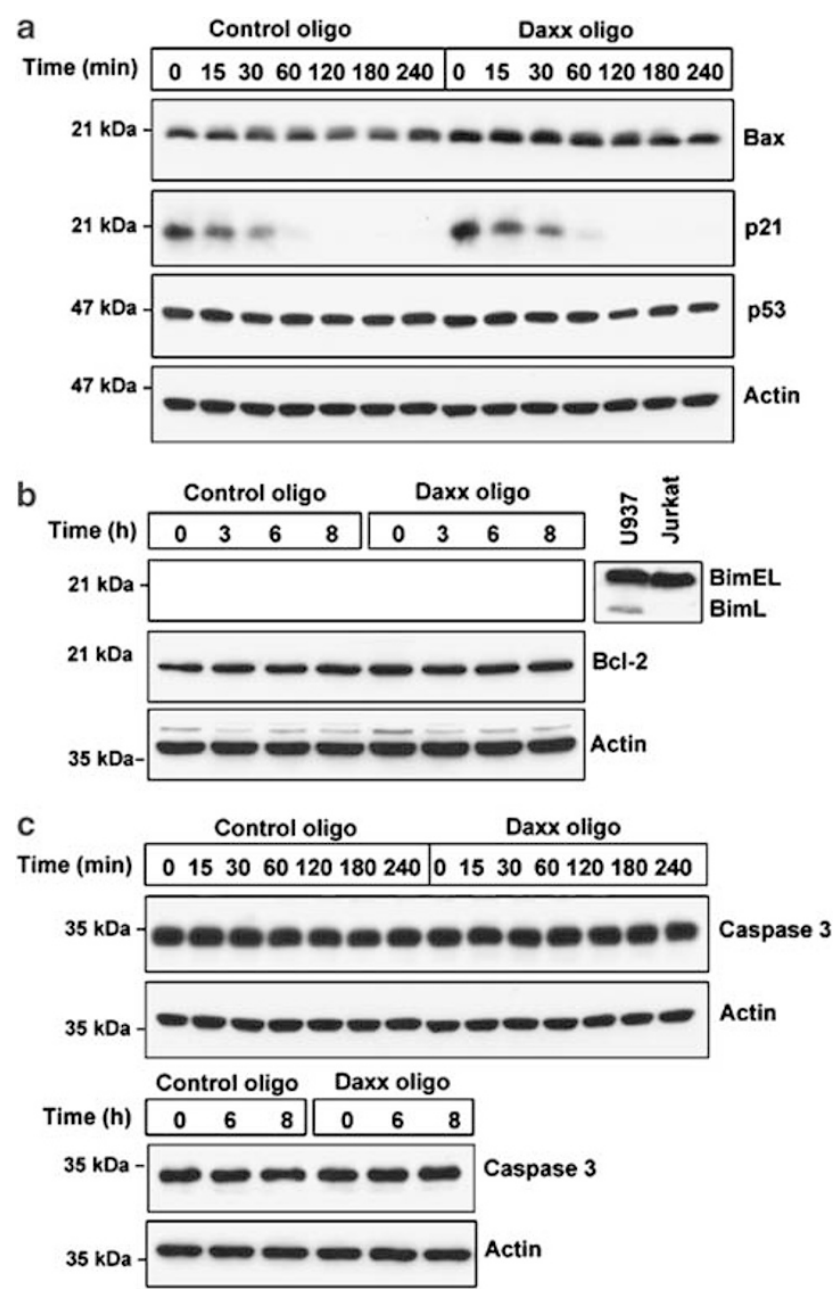

Figure 5 Daxx silencing does not affect the $p 53$ pathway, Bcl2 family members or caspases upon UV exposure. BJ cells were exposed to UV-C irradiation (80 J/ $\mathrm{m}^{2}$ ) and cell lysates were prepared at the indicated time points. (a) Western blot analysis of the cell lysates shows no differential effects on Bax, p21 and p53 protein levels between control (SO-transfected) and Daxx-depleted cells. (b) Western blot analysis of the cell lysates shows that Bim is not expressed in BJ primary fibroblasts compared to Jurkat and U937 cells, and there is no differential effects on Bcl2 protein levels between controls and Daxx-depleted cells. (c) Western blot analysis of the cell lysates shows that there is no activation caspase- 3 at all the time points examined up to $8 \mathrm{~h}$ following UV exposure (upper and lower panels)

We then reasoned that the protection observed in Daxxdepleted cells against UV-induced cell death might be due to a shift in the balance between pro- and antiapoptotic factors, which has been shown to regulate cell fate upon different stresses. ${ }^{27}$ We investigated this hypothesis by examining the levels of the $\mathrm{Bcl} 2$ proapoptotic family members including Bim and Bak, and the prosurvival family members including $\mathrm{Bcl} 2$ and $\mathrm{Bcl}-\mathrm{X}_{\mathrm{L}}$. Figure $5 \mathrm{~b}$ shows that $\mathrm{Bim}$ is not expressed in $\mathrm{BJ}$ primary fibroblasts as compared to Jurkat and U937 cells. Furthermore, although Bak expression was very weak in these cells, no differences were found between controls and Daxx-depleted cells (not shown). With regard to the prosurvival factor Bcl2, again no differences were observed as shown in Figure $5 b$. On the other hand, Bcl- $X_{L}$ expression was also very weak in BJ cells (not shown).
As we failed to detect major differences in the expression of several Bcl2 family members, we studied whether the resistance of Daxx-depleted cells to UV-induced cell death was due to a differential cleavage of the downstream caspase-3. There is evidence that caspase- 3 activation is accelerated in Daxx overexpressing cells, ${ }^{8}$ whereas Daxx silencing was shown to lead to a decrease in caspase activation. $^{19}$ To examine this, Western blot analysis was carried out to determine the levels of the pro-form of caspase3 , which is required for UV-induced apoptosis. ${ }^{28}$ As can be seen from Figure $5 \mathrm{c}$, the levels of the pro-form were not affected at both early time points (upper panel) and up to $8 \mathrm{~h}$ following exposure to UV (lower panel). In order to test whether UV-induced cell death is caspase-independent in this system, we treated BJ with the broad caspase inhibitor zVADfmk, and found that cell death was not blocked (not shown). Furthermore, subdiploid peak analysis of propidium iodide-stained control and Daxx-depleted UV-irradiated cells revealed only minimal apoptosis induction, which does not fully account for the significant cell death measured by the trypan blue exclusion assay (see Supplementary Information, Figure S2b). Taken together, these results suggest that BJ cells likely die by a non-apoptotic and caspase-independent mechanism following UV irradiation.

\section{Effects of Daxx downregulation on the JNK pathway}

The JNK pathway was shown to be essential for UV- and $\mathrm{H}_{2} \mathrm{O}_{2}$-induced cell death. ${ }^{29-31}$ Several studies have reported that the overexpression of Daxx results in activation of the JNK pathway ${ }^{1,2}$ through interaction and activation of the upstream JNK kinase kinase ASK $1 .^{3,4}$ However, the role of Daxx in the regulation of the JNK pathway remains unclear because of contradictory reports showing no evidence of JNK activation in either human Daxx-overexpressing cells or following their stimulation with Fas. ${ }^{8}$ Therefore, the role of Daxx in the regulation of the JNK pathway was investigated here in Daxx-depleted primary fibroblasts upon UV and $\mathrm{H}_{2} \mathrm{O}_{2}$ exposure. In control cells, JNK is rapidly activated by UV, and peaks at $30 \mathrm{~min}$ while slowly declining at later time points (Figure 6a). By contrast, in Daxx-depleted cells, JNK phosphorylation was significantly impaired and declined more rapidly than in control cells (Figure 6a). It is also interesting to note that phosphorylation of the slower migrating JNK isoform was particularly affected by Daxx downregulation (Figure 6a). Moreover, examining the phosphorylation of the upstream activator of JNK, the MAP kinase kinase (MAPKK) MKK4/ SEK1, revealed that it is significantly impaired in Daxxdepleted cells (Figure 6b), suggesting that Daxx is likely regulating kinases upstream of JNK.

Upon $\mathrm{H}_{2} \mathrm{O}_{2}$ treatment $(300 \mu \mathrm{M})$, JNK phosphorylation occurred as early as $30 \mathrm{~min}$ and peaked at $60 \mathrm{~min}$ in controls, whereas it was also significantly delayed and impaired in Daxx-depleted cells (Figure 6c).

Finally, Daxx downregulation seems to be specifically affecting the JNK pathway since no differences in activation of p38 were observed between controls and Daxx-depleted cells (not shown). 


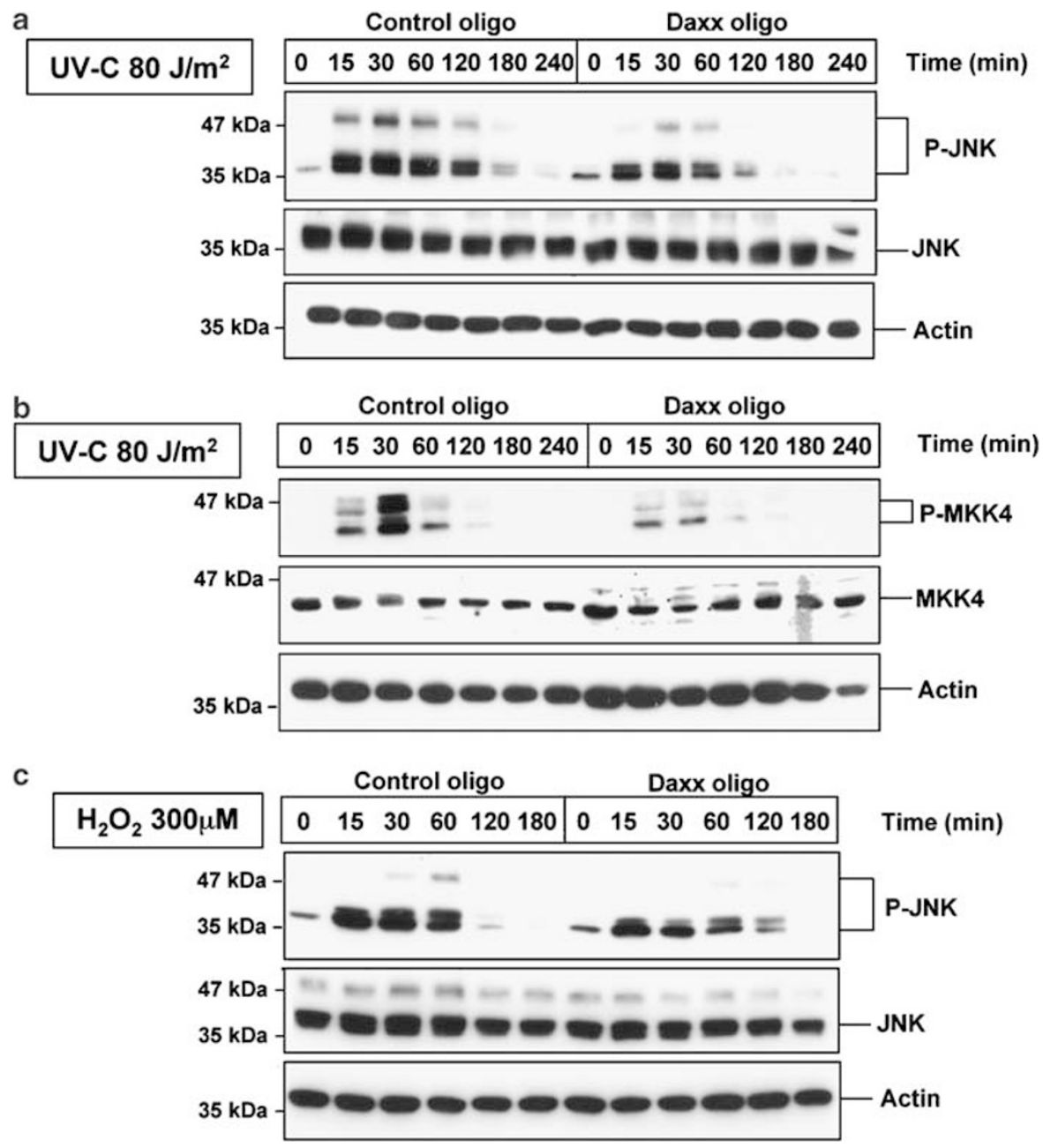

Figure 6 JNK activation is impaired in Daxx depleted cells following UV and $\mathrm{H}_{2} \mathrm{O}_{2}$ exposure. (a) BJ cells were exposed to UV-C irradiation ( $80 \mathrm{~J} / \mathrm{m}^{2}$ ) and cell lysates were prepared at the indicated time points. Western blot analysis of the cell lysates shows that JNK activation in Daxx-depleted cells is delayed and significantly impaired compared to control cells (SO-transfected). (b) BJ cells were exposed to UV-C irradiation $\left(80 \mathrm{~J} / \mathrm{m}^{2}\right)$ and cell lysates were prepared at the indicated time points. Western blot analysis of the cell lysates shows that phosphorylation/activation of the upstream JNK kinase MKK4 is also significantly impaired in Daxx-depleted cells compared to controls. (c) BJ cells were exposed continuously to $\mathrm{H}_{2} \mathrm{O}_{2}(300 \mu \mathrm{M})$ and cell lysates were prepared at the indicated time points. Western blot analysis of the cell lysates shows that JNK activation in Daxx-depleted cells is significantly impaired compared to controls

\section{Effects of UV and $\mathrm{H}_{2} \mathrm{O}_{2}$ treatments on the cellular localization of Daxx}

A number of reports have demonstrated that Daxx localizes into the PML-NB.$^{5-7}$ By contrast, other studies have reported the ability of Daxx to shuttle from the nucleus into the cytoplasm upon various stresses. ${ }^{4,10,32}$ In particular, during oxidative stress, Daxx was shown to rapidly relocalize to the cytoplasm and to activate the JNK pathway through ASK1. ${ }^{4,11}$ Nevertheless, the requirement for a cytoplasmic localization of Daxx to regulate cell death remains unclear. Here, we examined whether UV and $\mathrm{H}_{2} \mathrm{O}_{2}$ exposure induce rapid changes in the localization of Daxx, which could in turn affect the activation of the JNK pathway. To test this, we investigated the potential relocalization of Daxx at early time points following either UV-C irradiation $\left(80 \mathrm{~J} / \mathrm{m}^{2}\right)$ or $\mathrm{H}_{2} \mathrm{O}_{2}$ $(300 \mu \mathrm{M})$ treatment. The immunofluorescence images in Figure $7 \mathrm{a}$ clearly demonstrate that Daxx remains in the nucleus and is PML-NB-associated at 30 and 60 min following exposure of BJ cells to UV-C. Sub-cellular fractionation of control and UV-treated BJ cells clearly confirms that Daxx remains in the nuclear fraction following UV (Figure 7b). Furthermore, Daxx does not relocalize to the cytoplasm in BJ cells 30 and $60 \mathrm{~min}$ following continuous $\mathrm{H}_{2} \mathrm{O}_{2}$ treatment, contradicting previously reported data in tumour cell lines. ${ }^{4}$ Thus, following cellular stress Daxx is nuclear and remains associated to the PML-NB in primary cells.

\section{The upstream kinase ASK1 localizes to the nucleus}

We found in our primary cell system that Daxx is exclusively nuclear, and remains in the nucleus upon stress. Therefore, we reasoned that it could regulate upstream activators of the JNK pathway in the nucleus or, alternatively, induce their nuclear targeting. The most likely candidate is the Daxxinteracting kinase, ASK1, which is essential for JNK and p38 
a

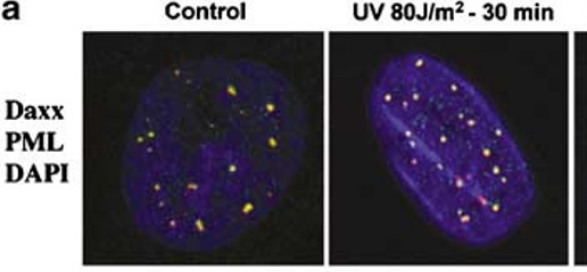

b

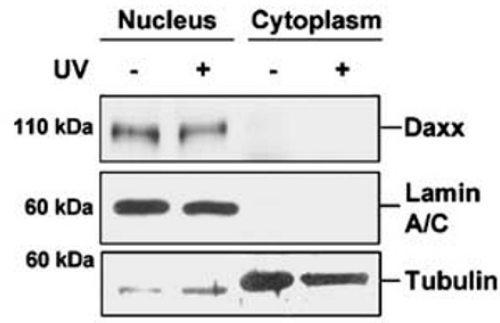

C
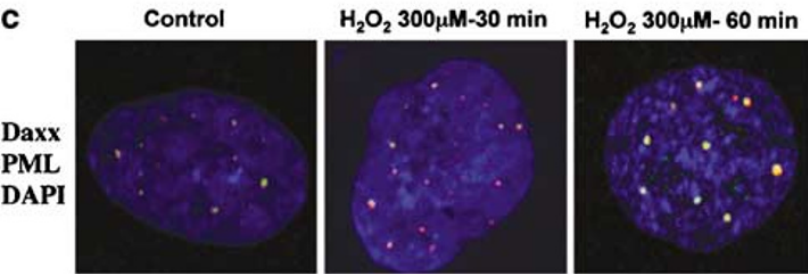

Figure 7 Daxx localization is not affected following exposure to stress. (a) $B J$ cells were treated with UV-C $\left(80 \mathrm{~J} / \mathrm{m}^{2}\right)$ and formalin-fixed at 30 or $60 \mathrm{~min}$ following irradiation. The merged confocal images show nuclear Daxx stained by immunofluorescence using an anti-Daxx antibody (green), PML stained using an anti-PML antibody (red) and the nuclei counterstained with DAPI (blue). (b) Western blot analysis of nuclear and cytoplasmic fractions of control and UVtreated BJ cells showing no Daxx shuttling into the cytoplasm following UV treatment. Lamin $\mathrm{A} / \mathrm{C}$ and Tubulin were measured as loading controls for nuclear and cytoplasmic fractions, respectively. (c) BJ cells were treated with $\mathrm{H}_{2} \mathrm{O}_{2}$ $(300 \mu \mathrm{M})$ and formalin-fixed at 30 or $60 \mathrm{~min}$ following continuous exposure. The merged confocal images show nuclear Daxx stained by immunofluorescence using an anti-Daxx antibody (green), PML stained using an anti-PML antibody (red) and the nuclei counterstained with DAPI (blue)

activation following cellular stress. ${ }^{31,33}$ We examined the localization of endogenous ASK1 by subcellular fractionation and found that, despite previous reports, ${ }^{4,9}$ it is both nuclear and cytoplasmic (Figure 8a). Several ASK1 reactive bands were readily detectable, two of which comigrate with exogenous ASK1 and are immunoprecipitated by an antiASK1 antibody (Figure $8 \mathrm{a}$ and not shown). The nuclear accumulation of ASK1 was not affected by Daxx downregulation, thus indicating that Daxx does not regulate ASK1 localization (not shown). Since the commercially available anti-ASK1 antibodies are not suitable for immunocytochemistry studies of the endogenous protein, we transfected BJ cells with an HA-ASK1 expression vector and analysed its localization pattern following UV irradiation. While at steady state only approximately $30 \%$ of ASK 1 was nuclear, almost $50 \%$ was found in the nucleus at $30 \mathrm{~min}$ following irradiation (Figure $8 \mathrm{~b}$, upper and lower panel). This relocalization was transient, as more than $60 \%$ of ASK1 was found in the cytoplasm at $60 \mathrm{~min}$ (Figure $8 \mathrm{~b}$ lower panel). Nevertheless, we were unable to demonstrate that Daxx and ASK1 colocalize into the PML-NB, as ASK1 nuclear staining was predominantly diffuse. Overall, this evidence suggests that upon stress Daxx and ASK1 are both localized in the nucleus,

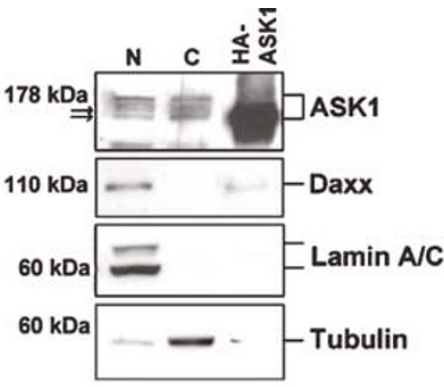

b
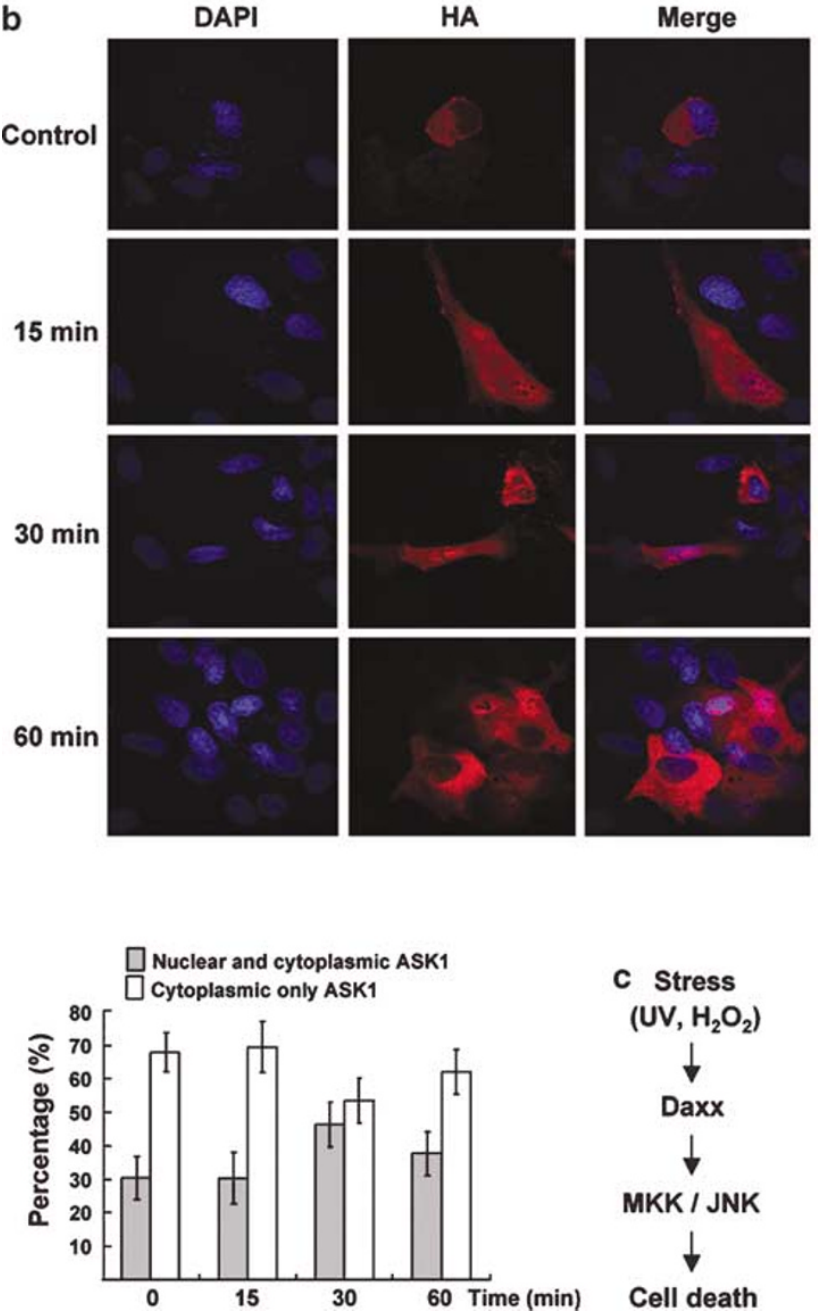

Figure 8 ASK1 is able to localize into nuclei of BJ cells. (a) ASK1 is found in nuclear $(\mathrm{N})$ and cytoplasmic $(\mathrm{C})$ fractions of $\mathrm{BJ}$ cells. Cells were fractionated as in Figure $7 \mathrm{~b}$. Nuclear and cytoplasmic fractions were run on SDS-PAGE and analysed by Western blotting using antibodies against ASK1 and Daxx. Lamin A/ $\mathrm{C}$ and Tubulin were measured as loading controls for nuclear and cytoplasmic fractions, respectively. (b) Upper panel shows confocal images of ASK1 relocalization to the nucleus upon UV. HA-ASK1-transfected BJ primary fibroblasts were exposed to UV-C $\left(80 \mathrm{~J} / \mathrm{m}^{2}\right)$ irradiation and formalin-fixed at the indicated time points following irradiation. Exogenous ASK1 was detected using an anti-HA antibody (red), and the nuclei were counterstained with DAPI (blue). Lower panel is a graph showing the nuclear versus cytoplasmic distribution of ASK1 following UV-C irradiation $\left(80 \mathrm{~J} / \mathrm{m}^{2}\right)$. An average of 82 transfected cells were counted per time point. Data are means of three experiments. Error bars are means \pm 1 standard error of the mean. (c) Daxx regulates the JNK pathway and cell death upon UV irradiation 
and therefore, Daxx could activate ASK1 in the nucleus, thus triggering the JNK pathway for cell death.

\section{Discussion}

The role of Daxx in cell death is still unclear and has become a controversial issue. Several reports have shown that Daxx overexpression potentiates apoptotic pathways such as the ones triggered by FAS and TGF- $\beta 1,{ }^{1,2,18}$ while only one study has reported that Daxx alone is able to induce cell death in primary cells. ${ }^{6}$ By contrast, Daxx downregulation by RNAi in tumour cell lines often results in either apoptosis or sensitization to several apoptotic stimuli, thus indicating that Daxx can also have antiapoptotic properties. ${ }^{14,21}$ Moreover, Daxx inactivation in the mouse dramatically disrupts embryogenesis leading to embryonic lethality and is associated with extensive cell death. ${ }^{20}$ Nevertheless, cell death is only slightly augmented in $\mathrm{Daxx}^{-/-}$cell lines, thus suggesting that the increased number of dead cells in the knockout embryo may be an indirect effect of Daxx inactivation. Overall, there is still no clear or convincing evidence for the role of Daxx in cell survival in physiological settings. In order to address this question, we developed a new method for delivering RNAi oligos into primary human fibroblasts and analysed the effects of Daxx downregulation. Surprisingly, Daxx silencing does not affect cell death at steady state, demonstrating that it is neither pro- nor antiapoptotic per se. Moreover, no effects on proliferation were observed. However, Daxx does regulate the cellular response to stress. We found that Daxx is induced at the protein level upon UV irradiation and oxidative stress triggered by $\mathrm{H}_{2} \mathrm{O}_{2}$. Strikingly, in the absence of Daxx BJ primary fibroblasts become resistant to cell death induced by either stimuli. Moreover, after UV irradiation, distinct morphological changes are evident in Daxx-depleted cells. These assume an elongated morphology and retain cell-cell contacts through long projections, thus suggesting that Daxx triggers changes in cytoskeletal structures (our unpublished observations). To our knowledge, this is the first indication that Daxx is required for cell death in physiological settings. There is evidence to suggest that the extent of cell death upon UV can also be regulated by the capacity of the cell to undergo cell cycle arrest to allow for DNA repair, ${ }^{34}$ so that in the presence of defective checkpoints nonarrested cells undergo massive cell death. ${ }^{34}$ However, in our system, Daxx-depleted cells do not display defects in cell cycle arrest upon UV, thus excluding this possibility as a potential explanation for the resistance to UV observed in Daxx-depleted cells.

In order to study the level at which Daxx regulates the cell death machinery, we examined the expression of several proand antiapoptotic molecules in Daxx-deficient cells. The expression of p53 and the p53 target genes Bax and p21 was not affected by Daxx silencing. Here it is worth noting that p53 is not induced by UV irradiation in this system, and neither is Bax. By contrast, p21 is downregulated upon UV exposure in both control and Daxx-deficient cells. This is not a surprising finding because of a recent report demonstrating that p21 is rapidly degraded following UV to allow for DNA repair. ${ }^{26}$ We also found that at later time points, p21 is reinduced in both control and Daxx-depleted cells (not shown). Furthermore, we did not observe differences in the expression levels of the Bcl2 family members $\mathrm{Bcl}-2, \mathrm{Bcl}-\mathrm{X}_{\mathrm{L}}$ and $\mathrm{Bak}$ between controls and Daxx-depleted cells. On the other hand, the $\mathrm{BH} 3$-only protein Bim, which has been implicated in UV-induced cell death, ${ }^{35}$ was not expressed in BJ cells. We also found that caspase-3 was not activated after irradiation in both control and Daxxdepleted cells and treatment with the broad caspase inhibitor, z-VADfmk, did not block UV-induced cell death. Accordingly, induction of apoptosis upon UV was minimal in this system (not shown). This suggests that UV-induced cell death is a caspase-independent and potentially nonapoptotic process in primary human fibroblasts and that Daxx can also regulate nonapoptotic types of cell death. These findings are not totally surprising, since primary fibroblasts are known to become susceptible to apoptotic cell death mainly when transduced with oncogenes such as E1A. ${ }^{36,37}$

Accumulating evidence indicates that Daxx can activate the JNK pathway by regulating the apical kinase ASK $1 .^{3,4}$ The JNK pathway is essential for UV-induced cell death in primary fibroblasts, as JNK1/JNK2-deficient cells are completely resistant to this type of cell death. ${ }^{38}$ Remarkably, we demonstrate here that the activation of JNK by UV is impaired and declines more rapidly in Daxx-deficient cells. JNK activation was also impaired upon oxidative stress. This is the first evidence that Daxx regulates JNK in primary cells. A recent report showed that the expression of a previously described dominant negative mutant of DAXX (C-Daxx) inhibits cell death and JNK activation upon UV. ${ }^{17}$ Paradoxically, overexpression of wild-type Daxx was shown to have the same effect, thereby casting doubts on the effectiveness of C-Daxx as a dominant negative in UV signalling. ${ }^{17}$ It is important to note that C-Daxx binds the FAS and TGF $\beta$ receptors and lacks the ability to activate the JNK pathway and therefore, has been demonstrated to act as a dominant negative only on FAS- and TGF $\beta 1$-induced JNK activation and apoptosis. ${ }^{1,18}$ Thus, the ability of C-Daxx to inhibit Daxxinduced cell death in other contexts still requires further investigation.

In the light of a recent report demonstrating that overexpressed Daxx relocalizes to the cytoplasm upon oxidative stress and that this correlates with the activation of the JNK pathway, ${ }^{4}$ we studied the localization of Daxx shortly after UV and $\mathrm{H}_{2} \mathrm{O}_{2}$ treatment in primary cells. Unlike previously reported, we found that Daxx is nuclear in both unstressed and stressed cells and accumulates in the PML-NB. Based on these findings, we hypothesize that Daxx could regulate the JNK pathway while residing in the nucleus. Daxx was shown to interact with and activate the apical MAPKKK ASK1, which is required for JNK activation and cell death in several systems. $^{3,4}$ We found that ASK1 is both nuclear and cytoplasmic in BJ cells and that its nuclear accumulation increases shortly after UV irradiation. Therefore, it is reasonable to suggest that Daxx could activate ASK1 in the nucleus. In addition, we found endogenous ASK1 in both cytoplasmic and nuclear fractions of BJ cells, thereby further strengthening a potential ASK1 activation by Daxx in the nucleus under physiological conditions. It is worth mentioning that we also found phosphorylated JNK in nuclear extracts of irradiated BJ cells, suggesting that several components of the JNK pathway might localize to the nucleus (not shown). Indeed, the JNK 
kinases MKK4 and MKK7 have been previously reported to localize to the nucleus. ${ }^{39}$

In conclusion, our study clearly demonstrates that Daxx is essential for stress-induced cell death and it is able to regulate the JNK pathway in physiological settings (Figure 8c). It will be of key importance to establish whether Daxx plays a broader role in the cellular response to DNA-damaging agents and toxicants.

\section{Materials and Methods}

\section{Materials}

All reagents used were from Sigma unless otherwise stated. Daxx small interfering RNA oligos D9 and D42 were purchased from Dharmacon and so was the Lamin A/C oligo. SO and Daxx D3 oligos were obtained from Ambion. The pcDNA3-HA-ASK1-WT plasmid, kindly provided by Professor Ichijo (University of Tokyo, Japan), was transfected into BJ using the lipofectamine reagent (Invitrogen).

\section{Antibodies}

Anti-human Daxx antibody was from Upstate Biotechnology. HRPconjugated secondary antibodies were from Amersham. Anti-mouse Daxx, Lamin A/C, ASK1, p53, Bax and PML antibodies were from Santa Cruz. Anti-caspase 8 and anti-caspase 3 antibodies were from Pharmingen. Anti-pJNK, JNK, pMKK4, MKK4 and p21 antibodies were from Cell Signalling Technology. Anti-actin and HA antibodies were from Sigma. Anti-Bcl-2 and Bim antibodies were from BD Biosciences.

\section{Cell culture}

Human primary fibroblasts from newborn foreskin, designated BJ, were purchased from the American Type Culture Collection (ATCC). They were cultured in Dulbecco's modified Eagle's medium (Invitrogen) supplemented with $20 \%$ fetal calf serum (Sera Laboratories International), $100 \mathrm{U} / \mathrm{ml}$ penicillin (Gibco), $100 \mu \mathrm{g} / \mathrm{ml}$ streptomycin (Gibco). Cells were grown in a humidified incubator at $37^{\circ} \mathrm{C}$ and $5 \% \quad \mathrm{CO}_{2} /$ air. Cells were only used between passages 10 and 18 .

\section{RNA interference for Daxx}

Three RNAi duplexes against human Daxx mRNA were used. The oligo sequences are as follows:

$$
\begin{array}{ll}
\text { D9 } & \text { GAAAUGCUACAAGCUGGAGtt (sense) } \\
& \text { CUCCAGCUUGUAGCAUUUCtt (antisense) } \\
\text { D42 } & \text { GCCAGGGCCUGAUACCUUCtt (sense) } \\
& \text { GAAGGUAUCAGGCCCUGGCtt (antisense) } \\
\text { D3 } & \text { GGUAAAGAUGGAGACAAGAtt (sense) } \\
& \text { UCUUGUCUCCAUCUUUACCtg (antisense) }
\end{array}
$$

The D9 and D42 oligos were synthesized by Dharmacon and directed against exons 2 and 3 of human Daxx, respectively. The D3 oligo was a prevalidated oligo from Ambion directed against exon 5 of human Daxx. The oligos were transfected by electroporation using a Bio-Rad X-Cell electroporator. Eight million cells were resuspended in $100 \mu \mathrm{l}$ OptiMEM serum-free medium (Invitrogen) and transferred into $2 \mathrm{~mm}$ electroporation cuvettes (Molecular BioProducts). Cells were electroporated at $160 \mathrm{~V}$ using an exponentially decaying pulse. Cell viability was determined following electroporation using the trypan blue exclusion assay.

\section{Western blotting}

Cells were lysed in RIPA lysis buffer containing $50 \mathrm{mM}$ Tris $\mathrm{pH} 7.6$, $150 \mathrm{mM}$ sodium chloride, $0.5 \%$ Triton- $\mathrm{X} 100,2.5 \mathrm{mM}$ sodium fluoride, $2 \mathrm{mM}$ sodium orthovanadate and a cocktail of protease inhibitors. Samples were analysed by SDS-PAGE, transferred onto a nitrocellulose membrane and probed with the relevant antibodies.

\section{Immunofluorescence}

Protein localization and expression were visualized by fluorescence microscopy. For this purpose, cells were grown on glass coverslips and fixed in $10 \%$ formalin. After washing with PBS, cells were permeabilized using 1\% Triton-X100 solution and blocked with $10 \%$ goat serum. Following incubation with the primary antibodies, cells were washed and incubated with fluorescently labelled secondary antibodies (Molecular Probes). The actin cytoskeleton was visualized by incubating cells with rhodamine-conjugated phalloidin (Molecular Probes). Stained slides were visualized using a Zeiss Axiovert $200 \mathrm{M}$ inverted microscope and a cooled CCD camera. Cellular localization of target proteins was carried out using confocal imaging. Images were processed using Adobe Photoshop 7.0.

\section{Cell death}

Cell death was assessed by the trypan blue exclusion assay. Floating and attached cells were collected and resuspended in full medium. An aliquot was diluted in a $0.4 \%$ trypan blue solution, and viable (trypan blue negative) and dead cells (trypan blue positive) were counted using a haemocyometer. Apoptosis was measured by propidium iodide staining of ethanol-fixed cells and subdiploid peak analysis.

\section{Subcellular fractionation}

For subcellular fractionation, BJ cells were plated in $150 \mathrm{~mm}$ dishes. Trypsinized cells were resuspended in ice-cold hypotonic buffer containing $10 \mathrm{mM}$ Hepes, $10 \mathrm{mM}$ magnesium chloride, $1 \mathrm{mM}$ EDTA, $1 \mathrm{mM}$ dithiothreitol (DTT), $2.5 \mathrm{mM}$ sodium fluoride, $2 \mathrm{mM}$ sodium orthovanadate and a cocktail of protease inhibitors. Cells were then homogenized on ice using a loose-fitting Dounce homogenizer. The homogenate was centrifuged at $1000 \times g$ for $10 \mathrm{~min}$ at $4^{\circ} \mathrm{C}$. The supernatant consisting of the cytoplasmic fraction was collected and diluted in Laemmli sample buffer, while the pellet consisting of the nuclear fraction was washed once in ice-cold hypotonic buffer and centrifuged at $1000 \times g$ for $10 \mathrm{~min}$ at $4^{\circ} \mathrm{C}$. The nuclear pellet was lysed in RIPA lysis buffer and centrifuged at maximum speed at $4^{\circ} \mathrm{C}$. The supernatant consisting of the soluble nuclear fraction was collected and diluted in Laemmli sample buffer. The cytoplasmic and soluble nuclear subcellular fractions were analysed by SDS-PAGE and Western blotting.

\section{Acknowledgements}

We thank Professor H Ichijo (Tokyo Medical and Dental University, Japan) for the HA-ASK1 expression vector, Professor P Nicotera, Professor G Cohen, Dr. Marion Macfarlane, Dr. V De Laurenzi, Cristian Bellodi (MRC, Toxicology Unit, Leicester, UK), Professor G Melino (University of Rome, Tor Vergata, Italy), Dr. F Bernassola (IDI-IRCCS, University of Rome Tor 
Vergata, Italy) and Dr. F Condorelli (Universita' del Piemonte Orientale, Novara, Italy) for reagents and helpful discussion. We also thank Sikand Kulvinder (MRC, Toxicology Unit, Leicester, UK) for confocal analysis. This work is supported by the Medical Research Council, UK.

\section{References}

1. Yang X, Khosravi-Far R, Chang HY and Baltimore D (1997) Daxx, a novel Fasbinding protein that activates JNK and apoptosis. Cell 89: 1067-1076

2. Chang HY, Yang X and Baltimore D (1999) Dissecting Fas signaling with an altered-specificity death-domain mutant: requirement of FADD binding for apoptosis but not Jun N-terminal kinase activation. Proc. Natl. Acad. Sci. USA 96: $1252-1256$

3. Chang HY, Nishitoh H, Yang X, Ichijo H and Baltimore D (1998) Activation of apoptosis signal-regulating kinase 1 (ASK1) by the adapter protein Daxx. Science 281: 1860-1863

4. Song JJ and Lee YJ (2003a) Catalase, but not MnSOD, inhibits glucose deprivation-activated ASK1-MEK-MAPK signal transduction pathway and prevents relocalization of Daxx: hydrogen peroxide as a major second messenger of metabolic oxidative stress. J. Cell. Biochem. 90: 304-314

5. Ishov AM, Sotnikov AG, Negorev D, Vladimirova OV, Neff N, Kamitani T, Yeh ET, Strauss III JF and Maul GG (1999) PML is critical for ND10 formation and recruits the PML-interacting protein Daxx to this nuclear structure when modified by SUMO-1. J. Cell Biol. 147: 221-234

6. Zhong S, Salomoni P, Ronchetti S, Guo A, Ruggero D and Pandolfi PP (2000) Promyelocytic leukemia protein (PML) and Daxx participate in a novel nuclear pathway for apoptosis. J. Exp. Med. 191: 631-640

7. Salomoni P and Pandolfi PP (2002) The role of PML in tumor suppression. Cell 108: $165-170$

8. Torii S, Egan DA, Evans RA and Reed JC (1999) Human Daxx regulates Fasinduced apoptosis from nuclear PML oncogenic domains (PODs). EMBO J. 18: 6037-6049

9. Ko YG, Kang YS, Park H, Seol W, Kim J, Kim T, Park HS, Choi EJ and Kim S (2001) Apoptosis signal-regulating kinase 1 controls the proapoptotic function of death-associated protein (Daxx) in the cytoplasm. J. Biol. Chem. 276: 39103-39106

10. Nefkens I, Negorev DG, Ishov AM, Michaelson JS, Yeh ET, Tanguay RM, Muller WE and Maul GG (2003) Heat shock and $\mathrm{Cd}^{2+}$ exposure regulate PML and Daxx release from ND10 by independent mechanisms that modify the induction of heat-shock proteins 70 and 25 differently. J. Cell Sci. 116 513-524

11. Song JJ and Lee YJ (2003b) Role of the ASK1-SEK1-JNK1-HIPK1 signal in Daxx trafficking and ASK1 oligomerization. J. Biol. Chem. 278: 47245-47252

12. Hollenbach AD, Sublett JE, McPherson CJ and Grosveld G (1999) The Pax3FKHR oncoprotein is unresponsive to the Pax3-associated repressor hDaxx. EMBO J. 18: 3702-3711

13. Li H, Leo C, Zhu J, Wu X, O'Neil J, Park EJ and Chen JD (2000) Sequestration and inhibition of Daxx-mediated transcriptional repression by PML. Mol. Cell. Biol. 20: 1784-1796

14. Michaelson JS and Leder $P$ (2003) RNAi reveals anti-apoptotic and transcriptionally repressive activities of DAXX. J. Cell Sci. 116: 345-352

15. Kim EJ, Park JS and Um SJ (2003) Identification of Daxx interacting with p73, one of the p53 family, and its regulation of $p 53$ activity by competitive interaction with PML. Nucleic Acids Res. 31: 5356-5367

16. Hollenbach AD, McPherson CJ, Mientjes EJ, lyengar R and Grosveld G (2002) Daxx and histone deacetylase II associate with chromatin through an interaction with core histones and the chromatin-associated protein Dek. J. Cell Sci. 115: $3319-3330$

17. Wu S, Loke HN and Rehemtulla A (2002) Ultraviolet radiation-induced apoptosis is mediated by Daxx. Neoplasia 4: 486-492
18. Perlman R, Schiemann WP, Brooks MW, Lodish HF and Weinberg RA (2001) TGF-beta-induced apoptosis is mediated by the adapter protein Daxx that facilitates JNK activation. Nat. Cell Biol. 3: 708-714

19. Kawai T, Akira S and Reed JC (2003) ZIP kinase triggers apoptosis from nuclear PML oncogenic domains. Mol. Cell. Biol. 23: 6174-6186

20. Michaelson JS, Bader D, Kuo F, Kozak C and Leder P (1999) Loss of Daxx, a promiscuously interacting protein, results in extensive apoptosis in early mouse development. Genes Dev. 13: 1918-1923

21. Chen LY and Chen JD (2003) Daxx silencing sensitizes cells to multiple apoptotic pathways. Mol. Cell. Biol. 23: 7108-7121

22. Bissonnette $N$ and Hunting DJ (1998) p21-induced cycle arrest in G1 protects cells from apoptosis induced by UV-irradiation or RNA polymerase II blockage. Oncogene 16: 3461-3469

23. Maltzman W and Czyzyk L (1984) UV irradiation stimulates levels of $p 53$ cellular tumor antigen in nontransformed mouse cells. Mol. Cell. Biol. 4: 16891694

24. Renzing J, Hansen S and Lane DP (1996) Oxidative stress is involved in the UV activation of p53. J. Cell Sci. 109 (Part 5): 1105-1112

25. Fridman JS and Lowe SW (2003) Control of apoptosis by p53. Oncogene 22: 9030-9040

26. Bendjennat M, Boulaire J, Jascur T, Brickner H, Barbier V, Sarasin A, Fotedar A and Fotedar R (2003) UV irradiation triggers ubiquitin-dependent degradation of p21(WAF1) to promote DNA repair. Cell 114: 599-610

27. Adams JM and Cory S (1998) The Bcl-2 protein family: arbiters of cell survival. Science 281: 1322-1326

28. Woo M, Hakem R, Soengas MS, Duncan GS, Shahinian A, Kagi D, Hakem A, McCurrach M, Khoo W, Kaufman SA, Senaldi G, Howard T, Lowe SW and Mak TW (1998) Essential contribution of caspase 3/CPP32 to apoptosis and its associated nuclear changes. Genes Dev. 12: 806-819

29. Chen YR, Wang X, Templeton D, Davis RJ and Tan TH (1996) The role of CJun $\mathrm{N}$-terminal kinase (JNK) in apoptosis induced by ultraviolet $\mathrm{C}$ and gamma radiation. Duration of JNK activation may determine cell death and proliferation. J. Biol. Chem. 271: 31929-31936

30. Saitoh M, Nishitoh H, Fujii M, Takeda K, Tobiume K, Sawada Y, Kawabata M, Miyazono K and Ichijo H (1998) Mammalian thioredoxin is a direct inhibitor of apoptosis signal-regulating kinase (ASK) 1. EMBO J. 17: 2596-2606

31. Tobiume K, Matsuzawa A, Takahashi T, Nishitoh H, Morita K, Takeda K, Minowa O, Miyazono K, Noda T and Ichijo H (2001) ASK1 is required for sustained activations of JNK/p38 MAP kinases and apoptosis. EMBO Rep. 2: 222-228

32. Charette SJ and Landry J (2000) The interaction of HSP27 with Daxx identifies a potential regulatory role of HSP27 in Fas-induced apoptosis. Ann. N.Y. Acad. Sci. 926: 126-131

33. Ichijo $H$, Nishida E, Irie $K$, ten Dijke $P$, Saitoh M, Moriguchi T, Takagi M, Matsumoto K, Miyazono K and Gotoh Y (1997) Induction of apoptosis by ASK1, a mammalian MAPKKK that activates SAPK/JNK and p38 signaling pathways. Science 275: 90-94

34. Shaulian E, Schreiber M, Piu F, Beeche M, Wagner EF and Karin M (2000) The mammalian UV response: c-Jun induction is required for exit from p53-imposed growth arrest. Cell 103: 897-907

35. Lei K and Davis RJ (2003) JNK phosphorylation of Bim-related members of the Bcl2 family induces Bax-dependent apoptosis. Proc. Natl. Acad. Sci. USA 100: 2432-2437

36. Lowe SW and Ruley HE (1993) Stabilization of the p53 tumor suppressor is induced by adenovirus 5 E1A and accompanies apoptosis. Genes Dev. 7: 535545

37. Debbas $M$ and White $E$ (1993) Wild-type p53 mediates apoptosis by E1A, which is inhibited by E1B. Genes Dev. 7: 546-554

38. Tournier C, Hess P, Yang DD, Xu J, Turner TK, Nimnual A, Bar-Sagi D, Jones SN, Flavell RA and Davis RJ (2000) Requirement of JNK for stress-induced activation of the cytochrome c-mediated death pathway. Science 288: 870-874

39. Tournier C, Whitmarsh AJ, Cavanagh J, Barrett T and Davis RJ (1999) The MKK7 gene encodes a group of $c$-Jun NH2-terminal kinase kinases. Mol. Cell. Biol. 19: 1569-1581

Supplementary Information accompanies the paper on Cell Death and Differentiation website (http://www.nature.com/cdd) 